\title{
Yenidoğan yoğun bakım ünitesinde prematürelerde nozokomiyal sepsis
}

\author{
Nosocomial sepsis in premature infants at neonatal intensive care unit
}

\author{
Eyüp Sarı \\ Department of Pediatrics, Dr. Sami Ulus Training and Research Hospital, Ankara, Turkey
}

\section{Özet}

Amaç: Yenidoğan Yoğun Bakım Ünitesinde Yatan Prematüre Bebeklerde nozokomiyal sepsis gelişme oranını, risk faktörlerini ve en sık görülen mikroorganizmaları saptamayı amaçladık.

Gereç ve Yöntem: Nozokomiyal sepsis grubunda (NSG) 46, kontrol grubunda (KG) ise 124 hasta olarak toplam 170 prematüre çalışma kapsamına alınmıştır. Tüm hastaların cinsiyet, doğum ağırlığı (DA), gebelik yaşı (GY), yatış süresi ve doğum şekilleri, klinik ve laboratuvar bulguları kaydedilmiştir. Sepsis düşünülen hastalarda kan, beyin omurilik sIVISI (BOS), endo trakeal aspirat (ETA), boğaz, idrar ve göbek kültürleri alınmıştır.

Bulgular: Sepsis risk faktörlerini belirlemek için yapılan lojistik regresyon analizi sonucunda yatış süresi, düşük $D A$, emmeme, mama ile beslenme, ventilatör tedavisi ve kan transfuzyonu, prematürelerde nozokomiyal sepsisi istatiksel olarak anlamlı olarak artırdığı saptamıştır. Ayrıca klinik bulgulardan kusma, ateş, apne, konvülziyon, menenjit ve hipoterminin nozokomiyal sepsis gelişmesi bakımından anlamlı risk faktörleri olduğu tespit edilmiştir $(p<0.05)$. $C$ reaktif protein (CRP), ortalama platelet hacmi (OPV) artışı ve periferik yaymada toksik granülasyon artışı nozokomiyal sepsisli bebeklerde istatiksel olarak anlamlı bulunmuştur $(p=0.00000)$. Nozokomiyal sepsisli hastaların \%50'sinde kan, \%20.37 sinde idrar kültüründe üreme gözlenmiş. 46 hastanı 11 de Klebsiella pneumonia (\%40.74) izole edilirken sırasıyla S. Aureus (\%18.51), Pseudomonas ve E. coli (\%11.11) üremesi görülmüştür.

Sonuç: Nozokomiyal sepsis prematürelerde önemli morbidite ve mortalite nedeni olduğu için risk faktörlerinin ve enfeksiyon etkenlerinin saptanarak gerekli önlemlerin alınmasının morbidite ve mortaliteyi azaltacağını düşünüyoruz.

Anahtar Sözcükler: Yenidoğan yoğun bakım üniteleri; sepsis

\begin{abstract}
Introduction: We aimed to establish the nosocomial sepsis development rate, risk factors, and most frequently found microorganisms in premature infants observed in Neonatal Intensive Care Units (NICU).

Methods: A total of 170 premature infants with 46 from nosocomial sepsis group (NSG) and 124 premature infants from the control group (CG) were included in this study. Gender, birth weight (BW), gestational age (GA) hospital stay and birth types, the laboratory and clinical findings of all patients were recorded. Blood, cerebrospinal fluid(CSF), endotracheal aspirate (ETA), throat, urine, and umbilical culture samples of the patients believed to have sepsis were obtained.

Results: As a result of the logistic regression analysis conducted to establish sepsis risk factors, hospital stays, low BW, lack of sucking, ventilation treatment, and blood transfusion were established to statistically significantly increase nosocomial sepsis. In addition, vomiting, fever, apnoea, convulsion, meningitis, and hypothermia that are among clinical symptoms were found as the significant risk factors in terms of sepsis development. C-reactive protein (CRP), mean platelet volume (MPV) increase and toxic granulation peripheral smear were higher in newborns with nosocomial sepsis were found as statistically significant. Of the nosocomial sepsis patients, growth was observed in the blood of $50 \%$, and in urine of $20.37 \%$. While Klebsiella pneumonia was isolated in 11 of the 46 patients (40.74\%), also observed were S. Aureus (18.51\%), Pseudomonas, and E. coli (11.11\%) growth, respectivel.

Discussion and Conclusion: Since nosocomial sepsis constitutes a significant cause of morbidity and mortality in infants, we believe that establishing risk factors and infection factors and taking necessary precautions would lower morbidity and mortality.
\end{abstract}

Keywords: Neonatal intensive care units; sepsis.

Corresponding (illetişim): Eyüp Sarı, SBÜ Ankara Dr. Sami Ulus Kadın Doğum, Çocuk Sağlığı ve Hastalıkları Eğitim ve Araştırma Hastanesi, Çocuk Sağlığı ve Hastalıkları Kliniği, Ankara, Turkey

E-mail (E-posta): doktoreyup@hotmail.com

Received (Geliş Tarihi): 30.11.2018 Accepted (Kabul Tarihi): 16.01.2019 
$\mathrm{N}$ ozokomiyal sepsis tüm yenidoğan (YD) ünitelerinde önemli mortalite ve morbidite nedeni olup teknolojinin gelişimiyle birlikte mikroorganizmaların dağılımı ve sıklığıda gün geçtikçe değişmektedir. ${ }^{[1,2]}$ Nozokomiyal sepsis, YD Yoğun Bakım Ünitesi (YYBÜ)'ne yatan olgular arasında yatışta sepsis bulguları ve kan kültürlerinde üreme olmayıp, 48 saat sonra bakteriyemi ile birlikte sistemik enfeksiyon bulgularının bulunması olarak tanımlanmaktadır. ${ }^{[1,3]}$ Nozokomiyal sepsis hastanede uzun süre kalması gereken düşük doğum ağırlıkı bebeklerde daha sık olup enfeksiyon, herhangi bir patojenle kolonize olmuş kişilerden veya kontamine ekipten kaynaklanır ve sporadik veya epidemiler halinde seyredebilir. ${ }^{[2,4]}$ Nozokomiyal sepsiste son yıllarda önemli değişiklikler olmuştur, bazı mikroorganizmalar önemini halen korurken bazıları da giderek artan oranda izole edilmeye başlanmıştır. Yapılan çaIışmalarda zamanında doğmuş bebeklerde nozokomiyal sepsis oranı \%0.5-1.7 iken, prematüre ve düşük doğum ağırlıklı bebeklerde \%20-33 olarak bildirilmektedir. ${ }^{[5,6]}$ YD sepsisinin insidansı prematürelik oranına, prenatal tedavi olanaklarına, doğum sırasındaki olaylara ve YD servisinin koşullarına göre değişmekte olup yapılan bir çalışmada YYBÜ'sinde nozokomiyal sepsis oranı \%5 olarak bildirilmiştir. ${ }^{[5]}{ }^{\text {YD'ın prematüre }}$ oluşu, düşük doğum ağırlıklı gibi özelliklerinin yanı sıra hastanede kalış süresinin uzun olması, deri ve mukoza bariyerini bozan travmalara, invasiv girişimlere maruz kalması ve uzun süreli geniş spektrumlu antibiyotiklerin kullanımı, YYBÜ'lerinde nozokomiyal sepsis riskini arttırmaktadır. ${ }^{[3,7,8]}$

Nozokomiyal sepsisde mortalite yüksektir ve çeşitli merkezlere göre değişmektedir. ${ }^{[2,9]}$ Yapılan bir çalışmada kültürle kanıtlanmış neonatal sepsis ve/veya menenjit tanılı 334 YD incelenmiş ve mortalite \%7.5 olarak bulunmuştur. ${ }^{[10]}$ Mortaliteyi arttıran birçok faktör olup, özellikle de prematürelerin immün sistemlerinin gelişmemiş olması, YYBÜ'nde uygulanan invaziv girişimler ve etyolojik ajanların özelliği en önemlileridir. ${ }^{[9,11]}$ Nozokomiyal sepsiste sorumlu mikroorganizmalar ise YD ünitesinin florasına bağlı olup koagülaz (-) Staphylococus, Staphylococus aureus, E. coli, ve Klebsiella türleri sık rastlanan mikroorganizmalardır, daha seyrek olarak Pseudomanas türlerinin de sepsise yol açtığı gözlenmiştir. ${ }^{[12-14]}$

Bu çalışmada hastanemizin YYBÜ'sinde bir yıl süreyle izlenen prematüre bebeklerde nozokomiyal sepsis gelişme oranını, risk faktörlerini ve en sık görülen mikroorganizmaları saptamayı amaçladık.

\section{Gereç ve Yöntem}

Çocuk Hastalıkları Merkezi YYBÜ'e 1 yıl boyunca yatan prematüre bebeklerde yerel etik kurul onayı ile prospektif olarak yapılan bu çalışmada toplam 170 prematüre çalışma kapsamına alınmıştır. Yoğun bakıma yatışta sepsis bulguları ve kan kültürlerinde üreme olmayıp, 48 saat sonra genel durumu kötüleşen kan ve/veya BOS kültüründe üreme olan hastalar nozokomiyal sepsis olarak kabul edilmiştir. ${ }^{[1,4]}$ Sepsis incelemeleri yapılmış ve kan ya da BOS kültüründe üreme saptanarak kesin sepsis tanısı alan 46 prematüre nozokomiyal sepsis grubunu (NSG), diğer 124 prematüre ise kontrol grubunu (KG) oluşturmuşlardır. Tüm hastaların cinsiyet, doğum ağırlığı (DA), gebelik yaşı (GY), yatış süresi, exutus oranları, nozokomiyal nepsis gelişme süresi (NS), normal doğum (ND), sezaryenle doğum (C/S), erken membran rüptürü (EMR), perinatal asfiksi kaydedilmiştir.

Her hastaya YYBÜ'e yattığında; hemoglobin, hematokrit, lökosit, trombosit, C reaktif protein (CRP), İmmatür nötrofil/total nötrofil (i/T) oranı, ortalama trombosit hacmi (MPV) ve toksik granülasyon (TG) gibi labaratuar bulguları kaydedilmiştir. Sepsis düşünülen hastalarda lumbal ponksiyon (LP) uygulanıp beyin omirilik sıVIsı (BOS) incelemesi yapılmış ve BOS kültürleri alınmıştır. Ventilatör tedavisi gören hastalardan endo trakeal aspirat (ETA ve boğaz kültürü, gereken hastalardan da idrar, göbek kültürleri alınmıştır.

Hastaların YYBÜ'de yattıkları süre içinde mekanik ventilasyon desteği, beslenme durumları, kan transfüzyonu, klinik bulguları, kaydedilmiş ve en sık üreyen mikroorganizmalar ile üreme yerleri saptanmaya çalışılmıştır.

İstatiksel değerlendirme: İstatistik analizler SPSS istatistik paket programı (SPSS Inc. Chicago, IL) kulanılarak yapılmıştır.Grupların karşılaştırılmasında ölçülebilir değerler için Mann-Whitney U-Wilcoxon Rank Sum W testi, ölçülemeyen değerler için ise Pearson ki-kare testi kullanılmış ve $p<0.05$ anlamlı olarak kabul edilmiştir. Nozokomiyal sepsis grubu için risk faktörlerini, anlamlı klinik ve laboratuar bulgularını saptamak için Pearson ki-kare testi kullanılmış ve Odds Ratio (OR) ve $\% 95$ güven aralığı (Confıdence Interval: $\mathrm{Cl}$ ) hesaplanarak Relatif Risk (RR) bulunmuştur. Anlamlı bulunan risk faktörleri için de multipl lojistik regresyon analizi kullanılarak ilişkin risk Attributable Risk (AR) oranı hesaplanmıştır.

\section{Bulgular}

Çalışmaya 46'sında nozokomiyal sepsis gelişen toplam 170 preterm bebek alınmıştır. Nozokomiyal sepsis gurubu hastalarının 22'si kız 24'ü erkek iken kontrol gurubunda 124 hastanın 49'u kız, 75'i erkek idi. Gebelik yaşı nozokomiyal sepsis gurubunda $32.17 \pm 3.16$ hafta, kontrol gurubunda $31.71 \pm 3.32$ haftaydı. Doğum ağırlığı nozokomiyal sepsis gurubunda $1718.26 \pm 445.40 \mathrm{gr}$, kontrol gurubunda $1890.91 \pm 490.60 \mathrm{gr}$ olarak bulunmuştur. Tablo 1'de görüldüğü gibi gruplar arasında cinsiyet GY ve DA bakımından fark bulunmamaktadır ( $>>0.05$ ). Hastalarımızda nozokomiyal sepsis en erken 2 , en geç 26. gün olmak üzere ortalama $10.15 \pm 6.21$ günde gelişmiştir. Her iki grubunda ND, C/S, EMR ve perinatal asfiksi gibi doğum sırasındaki problemlerle mekanik ventilasyon desteği, mama ile beslenme, Nazogastrik (NG) beslenme, kan transfüzyonu gibi doğum sonrası karşılaşılan risk faktörleri bakımından birbiri ile karşılaştırılmıştır (Tablo 1).

Nozokomiyal sepsis gurubunda 46 hastanın 4'ü eksitus olurken kontrol gurubunda e ise 124 hastanın 28'i (\%22.5) eksitus olmuştur. Bu hastaların 19'u yatışlarının ilk 48 saati içinde, kalan 9'u ise yatışlarından 48 saat sonra kaybedilmişlerdir. Nozokomiyal sepsis tanımı göz önüne alınarak (yatıştan 48 saat sonra enfeksiyonun gelişmesi), nozokomiyal sepsis'de eksitus olan hasta sayısı $(n=4, \% 8.69)$ ile KG'deki yatıştan 48 saat sonra 
Tablo 1. Hastaların demografik ve klinik özellikleri

\begin{tabular}{|c|c|c|c|c|}
\hline & \multicolumn{2}{|c|}{ NSG $(n=46)$} & \multicolumn{2}{|c|}{ KG $(n=124)$} \\
\hline & $\mathbf{n}$ & $\%$ & $\mathbf{n}$ & $\%$ \\
\hline \multicolumn{5}{|l|}{ Cinsiyet } \\
\hline Erkek & 24 & 52.17 & 75 & 60.48 \\
\hline $\mathrm{K} \mathrm{Iz}$ & 22 & 47.83 & 49 & 39.52 \\
\hline Gebelik yaşı (hafta) Ort. $\pm S S$ & \multicolumn{2}{|c|}{$32.17 \pm 3.16$} & \multicolumn{2}{|c|}{$31.71 \pm 3.32$} \\
\hline Doğum ağırlığı (gr) Ort. $\pm S S$ & \multicolumn{2}{|c|}{$1718.26 \pm 445.40$} & \multicolumn{2}{|c|}{$1890.91 \pm 490.60$} \\
\hline Yatış süresi (gün) Ort. $\pm S S$ & \multicolumn{2}{|c|}{$40.85 \pm 16.79$} & \multicolumn{2}{|c|}{$22.59 \pm 18.41$} \\
\hline \multicolumn{5}{|l|}{ Exutus } \\
\hline$\leq 48$ saat & - & - & 19 & 15.32 \\
\hline$>48$ saat & 4 & 8.69 & 9 & 7.25 \\
\hline NS gelişme süresi (gün) Ort. \pm SS & \multicolumn{2}{|c|}{$10.15 \pm 6.21$} & & \\
\hline \multicolumn{5}{|l|}{ NS gelişme süresi (gün) } \\
\hline $2-7$ & 19 & 41.30 & & \\
\hline $8-14$ & 17 & 36.95 & & \\
\hline$>14$ & 10 & 21.73 & & \\
\hline \multicolumn{5}{|l|}{ Doğum şekli } \\
\hline ND & 34 & 73.91 & 102 & 82.25 \\
\hline $\mathrm{C} / \mathrm{S}$ & 12 & 26.09 & 22 & 17.75 \\
\hline EMR & 10 & 21.73 & 31 & 25.0 \\
\hline Perinatal asfiksi & 10 & 21.73 & 13 & 10.48 \\
\hline Mekanik ventilasyon & 10 & 21.73 & 12 & 9.67 \\
\hline Mama ile beslenme & 44 & 95.65 & 21 & 16.93 \\
\hline NG Beslenme & 28 & 60.86 & 26 & 20.96 \\
\hline Kan transfüzyonu & 20 & 43.47 & 11 & 8.87 \\
\hline
\end{tabular}

NSG: Nozokomiyal sepsis grubu; KG: Kontrol grubu; NS: Nozokomiyal sepsis; Ort.: Ortalama; SS: Standart sapma; ND: Normal doğum; C/S: Sezaryenle doğum; EMR: Erken membran rüptürü; NG: Nazogastrik.

eksitus olan hasta sayısı ( $\mathrm{n}=9, \% 7.25)$ karşılaştırılmış ve arada anlamlı fark saptanmamıştır ( $\mathrm{p}>0.05$ ).

Tablo 2'de görüldüğü gibi nozokomiyal sepsis risk faktörlerinin multipl lojistik regresyon analizi yapıldığında Yatış süresi, $D A<1500$ gr olması, emmeme, formül mama ve NG ile beslenme, ventilatör tedavisi ve kan transfuzyonunun prematürelerde Nozokomiyal Sepsisi istatiksel olarak anlamlı olarak artırdığı saptamıştır ( $p<0.05)$. Ayrıca klinik bulgulardan kusma, ateş, apne, konvülziyon, menenjit ve hipoterminin nozokomiyal sepsis gelişmesi bakımından anlamlı risk faktörleri olduğu tespit edilmiştir $(p<0.05)$.

Laboratuvar bulguları karşılaştırıldığında Tablo 3'te görüldüğü gibi hemoglobin hematokrit, lökosit, trombosit, değerleri nozokomiyal sepsis gurubuna göre kontrol gurubunda anlamlı olarak daha yüksek bulunurken (sırasıyla $p=0.00094$, $0.00077,0.000,0.000)$. CRP (17.45 $\pm 21.21 ; 3.47 \pm 11.51), \mathrm{I} / \mathrm{T}$ $(0.15 \pm 0.9 ; 0.06 \pm 0.09)$, aksine ortalama platelet hacmi (OPV) artışı (\%80.43; \%19.35) ve periferik yaymada toksik granülasyon artışı (\%86.95; \%25.0) nozokomiyal sepsis gurubunada daha fazla olup istatiksel olarak anlamlı bulunmuştur $(p=0.00000)$.

Nozokomiyal Sepsisli hastaların \%50'de kan, \%20.37 de idrar kültüründe üreme gözlenmiş olup kültür üremeleri yerleri ve üreyen ajanlar Tablo 4'te verilmiştir. Kültürlerde en çok üreyen mikroorganizma Klebsiella pneumonia'dır. Klebsiella pneumonia; 11 kan, 6 İdrar, 2 BOS, 1 göbek ve 1 boğaz kültürü olmak üzere toplam 21 kültürde, S. Aureus ise 5 kan, 2 idrar, 1 göbek ve 1 ETA kültürü olmak üzere toplam 9 kültürde izole edilmiştir. Pseudomonas 3. sıklıkta enfeksiyon etkeni olup 3 kan, 3 ETA ve 2 boğaz kültürü olmak üzere toplam 8 kültürde tespit edilmiş ve 3 kan, 1 idrar, 3 ETA ve 1 boğaz kültürü olmak üzere toplam 5 kültürde de $E$. coli izole edilmiştir.

\section{Tartışma}

YYBÜ nozokomiyal sepsis antibiyotik tedavisindeki yeni gelişmeler, YB şartlarının ilerlemesi, immunoterapi ve tüm teknik ilerlemelere rağmen halen önemli bir morbidite ve mortalite nedeni olarak önemini korumaktadır. ${ }^{[9,15,16]}$

GY küçüldükçe ve hastanede kalış süresi arttıkça nozokomiyal enfeksiyon insidansı artmakta olup zamanında doğan bebeklerde \%0.5-1.7 oranında gözlenirken Düşük DA (DDA) olan bebeklerde ise \%20-33 oranında bildirilmektedir. ${ }^{[2]}$ Yapılan bir çalışmada YYBÜ de nozokomiyal sepsis oranı \%5,7 olarak bildirilmiştir. ${ }^{[17]}$ Samancı ve ark. ${ }^{[18]}$ yaptığı çalışmada ise YYBÜ'de görülen sepsislerin \%91.6 nın prematüre olduğunu, nozoko- 
Tablo 2. Nozokomiyal sepsis risk faktörlerinin multipl lojistik regresyon analizi

\begin{tabular}{|c|c|c|c|c|c|c|c|}
\hline & \multicolumn{2}{|c|}{ NSG $(n=46)$} & \multicolumn{2}{|c|}{ KG $(n=124)$} & \multirow[t]{2}{*}{ p-value } & \multirow[t]{2}{*}{ OR } & \multirow[t]{2}{*}{$95 \% \mathrm{Cl}$} \\
\hline & $\mathbf{n}$ & $\%$ & $\mathbf{n}$ & $\%$ & & & \\
\hline Yatış süresi, Ort. \pm SS & \multicolumn{2}{|c|}{$40.85 \pm 16.79$} & \multicolumn{2}{|c|}{$22.59 \pm 18.41$} & 0.00000 & 20.85 & $23.68-18.02$ \\
\hline $\mathrm{DA}<1500 \mathrm{gr}$ & 21 & 45.65 & 19 & 15.32 & 0.00003 & 2.73 & $1.72-4.32$ \\
\hline DDA & 25 & 54.34 & 46 & 37.09 & 0.04274 & 1.65 & $1.01-2.71$ \\
\hline Emmeme & 45 & 97.82 & 58 & 46.77 & 0.00000 & 29.27 & $4.13-207.31$ \\
\hline Formül mama & 44 & 95.65 & 21 & 16.93 & 0.00000 & 55.53 & 8.91-14.66 \\
\hline NG sonda & 28 & 60.86 & 26 & 20.96 & 0.00000 & 3.34 & $2.03-5.48$ \\
\hline Ventilatör tedavisi & 10 & 21.73 & 12 & 9.67 & 0.03739 & 1.86 & $1.09-3.20$ \\
\hline Kan transfüzyonu & 20 & 43.47 & 11 & 8.87 & 0.00000 & 3.44 & $2.35-5.32$ \\
\hline Kusma & 22 & 47.82 & 13 & 10.48 & 0.00000 & 3.53 & $2.26-5.50$ \\
\hline Ateş & 5 & 10.86 & - & - & 0.00019 & 4.02 & $3.08-5.24$ \\
\hline Apne & 20 & 43.47 & 23 & 18.54 & 0.00089 & 2.27 & $1.42-3.63$ \\
\hline Konvülziyon & 5 & 10.86 & 3 & 2.41 & 0.02081 & 4.35 & $3.27-5.77$ \\
\hline Menenjit & 9 & 19.56 & - & - & 0.00000 & 4.35 & $3.27-5.77$ \\
\hline Hipotermi & 14 & 30.43 & 19 & 15.32 & 0.02688 & 1.81 & $1.10-2.99$ \\
\hline
\end{tabular}

NSG: Nozokomiyal sepsis grubu; KG: Kontrol grubu; OR: Odds ratio; Cl: Confidence interval; Ort.: Ortalama; SS: Standart sapma; NG: Nazo gastrik; DA: Doğum ağırlığı; DDA: Düşük doğum ağırlığı.

Tablo 3. Nozokomiyal sepsiste laboratuar bulgularının multipl lojistik regresyon analizi

\begin{tabular}{|c|c|c|c|c|c|}
\hline & NSG $(n=46)$ & KG $(n=124)$ & $\mathbf{p}$ & OR & (\%95CI) \\
\hline Hematokrit (\%), Ort. \pm SS & $38.60 \pm 9.16$ & $44.7 \pm 806$ & 0.00077 & 2.28 & $1.40-3.69$ \\
\hline Trombosit $\left(/ \mathrm{mm}^{3}\right)$, Ort. $\pm \mathrm{SS}$ & $164.23 \pm 133.39$ & $216.15 \pm 130.28$ & 0.00000 & 3.47 & $2.21-5.44$ \\
\hline CRP (mg/dL), Ort. $\pm S S$ & $17.45 \pm 21.21$ & $3.47 \pm 11.51$ & 0.00000 & 11.08 & $5.56-22.05$ \\
\hline $\mathrm{TG}(+) \mathrm{n},(\%)$ & $40(86.95)$ & $31(25.0)$ & 0.00000 & 9.29 & $4.16-20.73$ \\
\hline
\end{tabular}

NSG: Nozokomiyal sepsis grubu; KG: Kontrol grubu; OR: Odds ratio; Cl: Confidence interval; Ort.: Ortalama; SS: Standart sapma; CRP: C-Reaktif protein; I/T: Immatür nötrofil/total nötrofil; MPV: Ortalama trombosit hacmi; TG: Toksik granülasyon.

miyal sepsis oranını da \%4 olarak saptamışlar. Hemming ${ }^{[19]}$ ise araştırmasında nozokomiyal sepsis oranını \%24.6 olarak bildirmiştir. Bizde çalışmamızda prematüre hastalarda nozokomiyal sepsis oranı \%27.1 olarak tespit ettik. GY küçüldükçe nozokomiyal sepsis insidansı artmaktadır $(7,20,85)$. Samancı ve ark. ${ }^{[18]}$ yaptığı çalışmada sepsisli hastaların ortalama GY: $32.4 \pm 2.3$ (25-43) gün ve DA: $1762 \pm 0.589$ (730-4250) gr olarak bildirmişlerdir. Bizim çalışmamızda nozokomiyal sepsisli hastaların


risk faktörü açısından istatiksel olarak anlamlı bulunmadı.

Literatürde nozokomiyal sepsis oranının DDA'ı bebeklerde daha fazla olduğu bildirilmektedir. ${ }^{[8,15,16]}$ Bizim çalışmamızda da NSG da DA'nın daha düşük (NSG:1718.26 \pm 445.40 ; KG:1890.91 \pm 490.60$)$ olduğunu DDA'nın nozokomiyal sepsis gelişmesi bakımından anlamlı risk faktörü oduğunu sapta$\operatorname{dik}(p=0.03739)$.
Literatürde hastanede kalış süresinin de nozokomiyal sepsisli hastalarda daha uzun olduğ ${ }^{[18,20]}$ ve yatış süresinin uzaması YD'nın muhtemel patojen gram (-) bakteriyal flora ile kolonizasyonuna yol açtığı bildirilmiştir. ${ }^{[18]}$ Bizim çalışmamızda nozokomiyal sepsisli hastaların ortalama yatış süresi $40.85 \pm 16.79$ (19-90) gün, sepsisli olmayan hastalarda ortalama yatış süresi $15.81 \pm 13.84$ gün olarak bulundu ve yapılan logistik regresyon analizinde de yatış süresinin artmasının nozokomiyal sepsis gelişme olasılığını artırdığı belirlendi $(p=0.0000)$. Kotloff ve ark. ${ }^{[8]} \mathrm{NS}^{\prime}$ li hastalarda sepsis gelişme süresini ortalama 28 gün olarak bildirilmişler ve lojistik regresyon analizi ile yatış süresi anlamlı bir risk faktörü olmadığı ancak doğum ağırlığı ile yüksek oranda ilişkili risk faktörü olduğunu bildirmişlerdir. Bizim çalışmamızda yatış süresi nozokomiyal sepsis gurubunda ortalama $40.85 \pm 16.79$ gün olup kontrol gurubunda ortalama yatış süresine (22.59 \pm 18.41 gün) göre istatiksel anlamlı 
Tablo 4. Nozokomiyal sepsisli hastaların kültür üremeleri yerleri ve üreyen ajanlar

\begin{tabular}{|c|c|c|c|c|c|c|c|c|c|c|}
\hline & \multicolumn{2}{|c|}{ Kan } & \multicolumn{2}{|c|}{ İdrar } & BOS & Göbek & ETA & Boğaz & \multicolumn{2}{|c|}{ Total } \\
\hline S. Aureus & 5 & 18.51 & 2 & & - & 1 & 1 & - & 9 & 16.66 \\
\hline E. coli & 3 & 11.11 & 1 & & - & 1 & - & - & 5 & 9.25 \\
\hline Pseudomonas & 3 & 11.11 & - & & - & - & 3 & 2 & 8 & 14.81 \\
\hline G-Diplococ & - & - & - & & 1 & - & - & - & 1 & 1.85 \\
\hline Acinobacter & - & - & - & & - & - & 1 & - & 1 & 1.85 \\
\hline Enterococ & - & - & 3 & & - & - & - & - & 3 & 5.55 \\
\hline Pnömococ & 1 & 3.70 & - & & - & - & - & - & 1 & 1.85 \\
\hline Candida & 2 & 7.40 & 2 & & - & - & - & - & 4 & 7.40 \\
\hline
\end{tabular}

BOS: Beyin omurilik sIVISI; ETA: Endo trakeal aspirat.

derecede yüksek olduğu gözlenmiştir ( $p=0.00000)$. Yapılan bir çalışmada ortalama yatış süresinin 22.1 gün olduğu ve invaziv girişimlerin nozokomiyal sepsis için risk faktörü olduğu bildirilmiştir. ${ }^{[18]}$ Nozokomiyal sepsis için risk faktörlerinin analiz edildiği diğer bir çalışmada ise ventilasyon desteğinin ve iV kateterin, NS için risk faktörü olduğunu raporlamışlardır. ${ }^{[8]}$ Tessin ve ark. ${ }^{[16]}$ invaziv girişimlerden en fazla exchange transftizyonunu risk faktörü olarak bulduklarını bildirmişlerdir. Bizim çalışmamızda ise NG sonda, transfüzyon ve ventilatör tedavisi NS de istatiksel olarak anlamlı derecede risk faktörü olduğu bulunurken ( $p<0.005)$, kateter, exchange ve sonda uygulaması nozokomiyal sepsis gurubunda daha yüksek oranda tespit edilmesine rağmen istatiksel olarak anlamlı bulunmadı ( $p>0.005)$. Yapılan başka bir çalışmada ise NS azaltmak için invaziv işlemler azaltılmış ve sonuçların olumlu olduğunu bildirmişlerdir. ${ }^{[21]}$ Anne sütü ile beslenmenin NS insidansını azalttığı ve anne sütü ile mama alan bebekler karşılaştırıldığında anne sütünün sepsise karşı koruyucu etkisi olduğu bildirilmektedir. [22] Bizim çalışmamızda anne sütü ve anne sütü + mama alan grup ile sadece mama alan grup karşılaştırıldı ve istatiksel olarak anlamlı olarak anne sütü alanlarda NS daha az gözlendiği tespit edildi $(\mathrm{p}=0.0000)$.

Klinik bulgulardan en sık \%97.8 oranında emmeme olmak üzere kusma, ateş, apne, konvülziyon, hipotermi ve menenjit sepsiste eşlik eden bulgular açısından anlamlı olarak nozokomiyal sepsis gurubunda daha fazla bulundu. Yapılan çalışmalarda ve literatürde neonatal sepsiste en sık gözlenen semptomların emmeme, hipotermi, ateş, irritabilite ve kusma olarak görülmektedir. ${ }^{[23]}$ Bu çalışmada da, nozokomiyal sepsis gurubunda da emmeme, menenjit ve kusma istatiksel olarak anlamlı derecede fazla gözlenen klinik bulgular olarak sapta$\operatorname{dık}(p=0.0000)$.

Laboratuvar bulgularına bakıldığında ise nozokomiyal sepsis gurubunda 40 hastanın periferik yaymasında nötrofillerde TG, 38 hastada CRP ve 37 hastada ise MPV artışı saptanmış- tır. Gruplar karşılaştırıldığında, TG (+) (\%86.95; \%25.0), CRP (17.45 $\pm 21.21 ; 3.47 \pm 11.51)$, MPV yüksekliği (\%86.95; \%25.0), I/T artışı, lökopeni, Hb, Htc düşüklüğü, trombositopeni istatiksel olarak anlamlı bulundu. Yapılan çalışmalarda bizim sonuçlarımızla uyumlu olarak neonetal sepsisli hastalarda $\mathrm{Hb}$, Htc, düşüklüğü, lökopeni, trombositopeni ve CRP artışının en sık gözlenen laboratuar bulguları olduğu bildirilmiştir. ${ }^{[24,25]}$ Ayrıca I/T artışını sepsisin erken tanısında önemli olduğunu ve I/T oranını kullanarak yapılan skorlama sisteminin önemini vurgulayan çalışmalar bulunmaktadır. ${ }^{[25-27]}$

Kan kültüründe ajan patojen üreme oranımız \%58 iken idrar kültüründe \%20.37 en düşük oranda \%5.55 oranla BOS ve boğaz kültüründe üreme gözlenmiştir. Klebsiella pneumonia (\%38.88) en fazla üreyen mikroorganizma olup bunu sırasıyla S. Aureus, Pseudomonas ve E. coli izlemiştir. Yapılan çalışmalarda nozokomiyal sepsis de en fazla oranda Klebsiella tespit edilmiştir. $^{[28,29]}$ Bhutta ve ark. ${ }^{[29]}$ yaptıkları çalışma da bizim çalışmamıza benzer şekilde 60 YD'nin 27'sinde (\%45) nozokomiyal sepsis gözlendiğini ve sepsise neden olan en yaygın organizmaların, Klebsiella türleri (\%53) ve E. coli (\%10) ve Pseudomonas (\%14) olduğunu bildirmişlerdir. Koagülaz (-) staphylococların birçok ülkede YBÜ'de nozokomiyal sepsisin sık nedeni olarak bildirilmektedir. Hemming ve ark. ${ }^{[19]}$ ise nozokomiyal sepsiste en fazla oranda (\%45) Staphyilococus aureus tespit etmişler ve aynı şekilde Kotloff ve ark. ${ }^{[8]}$ YYBÜ nozokomiyal sepsis çalışmalarında düşük doğum ağırlığı, yatış süresi ve mekanik ventilatör desteğinin neonetal sepsis için risk faktörü olduğunu kültürlerde en sık S. Aureus tespit ettiklerini bildirmişlerdir.

\section{Sonuç}

Nozokomiyal sepsis YD de önemli morbidite ve mortalite nedenidir. Bizim çalışmamızda nozokomiyal sepsis gelişen prematürelerde en sık Klebsiella pneumonia tespit edildi. Enfeksiyon etkenlerinin saptanarak gerekli önlemlerin alınmasının morbidite ve mortaliteyi azaltacağını düşünüyoruz. 
Çıkar çatışması: Bildirilmemiştir.

\section{Kaynaklar}

1. Allen U, Ford-Jones EL. Nosocomial infections in the pediatric patient: an update. Am J Infect Control 1990; 18(3):176-93.

2. Jacob J, Pfenninger J, Davis RF, Hulman S. The next challenge for newborn intensive care in Alaska: improving the survival of the larger neonate. Alaska Med 1997; 39(4):111-6.

3. Starr SE. Antimicrobial therapy of bacterial sepsis in the newborn infant. J Pediatr 1985; 106(6):1043-8.

4. Garner JS, Jarvis WR, Emori TG, Horan TC, Hughes JM. CDC definitions for nosocomial infections, 1988. Am J Infect Control 1988; 16(3):128-40.

5. Simon C, Schroder H, Beyer C, Zerbst T. Neonatal sepsis in an intensive care unit and results of treatment. Infection 1991; 19(3):146-9.

6. Mullett MD, Cook EF, Gallagher R. Nosocomial sepsis in the neonatal intensive care unit. J Perinatol 1998; 18(2):112-5.

7. Gayvallet-Montredon N, Sauvestre C, Bergeret M, Gendrel D, Raymond J. [Bacteriologic surveillance of nosocomial septicemia and bacteremia in a pediatric hospital]. Arch Pediatr 1998; 5(11):121620.

8. Kotloff KL, Blackmon LR, Tenney JH, Rennels MB, Morris JG, Jr. Nosocomial sepsis in the neonatal intensive care unit. South Med J 1989; 82(6):699-704.

9. Gerdes JS. Clinicopathologic approach to the diagnosis of neonatal sepsis. Clin Perinatol 1991; 18(2):361-81.

10. Perez EM, Weisman LE. Novel approaches to the prevention and therapy of neonatal bacterial sepsis. Clin Perinatol 1997; 24(1):213-29.

11. Wolach B. Neonatal sepsis: pathogenesis and supportive therapy. Semin Perinatol 1997; 21(1):28-38.

12. Maguire GC, Nordin J, Myers MG, Koontz FP, Hierholzer W, Nassif E. Infections acquired by young infants. Am J Dis Child 1981; 135(8):693-8.

13. Coovadia YM, Johnson AP, Bhana RH, Hutchinson GR, George RC, Hafferjee IE. Multiresistant Klebsiella pneumoniae in a neonatal nursery: the importance of maintenance of infection control policies and procedures in the prevention of outbreaks. J Hosp Infect 1992; 22(3):197-205.

14. Nataro JP, Corcoran L, Zirin S, et al. Prospective analysis of coagulase-negative staphylococcal infection in hospitalized infants.
J Pediatr 1994; 125(5 Pt 1):798-804.

15. St Geme JW, 3rd, Polin RA. Neonatal sepsis. Progress in diagnosis and management. Drugs 1988; 36(6):784-800.

16. Tessin I, Trollfors B, Thiringer K. Incidence and etiology of neonatal septicaemia and meningitis in western Sweden 1975-1986. Acta Paediatr Scand 1990; 79(11):1023-30.

17. Campins M, Vaque J, Rossello J, et al. Nosocomial infections in pediatric patients: a prevalence study in Spanish hospitals. EPINE Working Group. Am J Infect Control 1993; 21(2):58-63.

18. Samanci N, Ovali F, Akdoğan Z, Dağoğlu T. Neonatal septicemia in a neonatal intensive care unit. Results of four years. The Turkish journal of pediatrics 1997; 39(2):185-93.

19. Hemming VG, Overall JC, Jr., Britt MR. Nosocomial infections in a newborn intensive-care unit. Results of forty-one months of surveillance. N Engl J Med 1976; 294(24):1310-6.

20. Witek-Janusek L, Cusack C. Neonatal sepsis: confronting the challenge. Crit Care Nurs Clin North Am 1994; 6(2):405-19.

21. Ng SP, Gomez JM, Lim SH, Ho NK. Reduction of nosocomial infection in a neonatal intensive care unit (NICU). Singapore Med J 1998; 39(7):319-23.

22. el-Mohandes AE, Picard MB, Simmens SJ, Keiser JF. Use of human milk in the intensive care nursery decreases the incidence of nosocomial sepsis. J Perinatol 1997; 17(2):130-4.

23. Poland RL, Watterberg KL. Sepsis in the newborn. Pediatr Rev 1993; 14(7):262-3.

24. Shortland DB, MacFadyen U, Elston A, Harrison G. Evaluation of C. reactive protein values in neonatal sepsis. J Perinat Med 1990; 18(3):157-63.

25. Boyle RJ, Chandler BD, Stonestreet BS, Oh W. Early identification of sepsis in infants with respiratory distress. Pediatrics 1978; 6 2(5):744-50.

26. Rodwell RL, Leslie AL, Tudehope DI. Early diagnosis of neonatal sepsis using a hematologic scoring system. J Pediatr 1988; 112(5):761-7.

27. Benuck I, David RJ. Sensitivity of published neutrophil indexes in identifying newborn infants with sepsis. J Pediatr 1983; 103(6):961-3.

28. Prasertsom W, Horpaopan S, Ratrisawadi V, Puapondh Y, Thanasophon Y, Trakulchang K. Early versus late onset neonatal septicemia at Children's Hospital. J Med Assoc Thai 1990; 73(2):106-10.

29. Bhutta ZA, Naqvi SH, Muzaffar T, Farooqui BJ. Neonatal sepsis in Pakistan. Presentation and pathogens. Acta Paediatr Scand 1991; 80(6-7):596-601. 